\title{
Potassium Removal from Juices Using an Individual Single-Use Ion-Exchange Device
}

\author{
Alexander Pushkin ${ }^{1}$, Rachel Mund ${ }^{1}$, Anna Nadya Pushkin ${ }^{1}$, Allan Zevelev ${ }^{1}$, Debra Newman ${ }^{1}$, \\ Ofelia Berina $^{2}$, Maria Golchin², Ira Kurtz ${ }^{1, *}$ \\ ${ }^{1}$ Department of Medicine, D. Geffen School of Medicine at UCLA, Los Angeles, USA \\ ${ }^{2}$ Department of Pathology and Laboratory Medicine, D. Geffen School of Medicine at UCLA, Los Angeles, USA
}

Email address:

apushkin@mednet.ucla.edu (A. Pushkin),rmund2015@yula.org (R. Mund), annaapushkin@gmail.com (A. N. Pushkin), allanzevelev@yahoo.com (A. Zevelev),dkurtz@mednet.ucla.edu (D. Newman), OBerina@mednet.ucla.edu (O. Berina), mgolchin@mednet.ucla.edu (M. Golchin),ikurtz@mednet.ucla.edu (I. Kurtz)

${ }^{*}$ Corresponding author

\section{To cite this article:}

Alexander Pushkin, Rachel Mund, Anna Nadya Pushkin, Allan Zevelev, Debra Newman, Ofelia Berina, Maria Golchin, Ira Kurtz. Potassium Removal from Juices Using an Individual Single-Use Ion-Exchange Device. Journal of Food and Nutrition Sciences.

Vol. 5, No. 2, 2017, pp. 28-33. doi: 10.11648/j.jfns.20170502.12

Received: February 7, 2017; Accepted: February 28, 2017; Published: March 15, 2017

\begin{abstract}
There are more than 100 million patients with various stages of chronic kidney disease (CKD) with decrease in CKD1 to loss in CKD 5 (end stage renal disease, ESRD) in the ability of the kidney to excrete $\mathrm{K}^{+}$causing hyperkalemia and potentially heart attack. To avoid hyperkalemia, kidney patients have to drastically limit the consumption of fruit and vegetable juices that significantly decreases the nutritional value of their diet. Previous research using ion-exchange column chromatography demonstrated some efficiency in the $\mathrm{K}^{+}$removal from juices without pulp, whereas no approaches have been generated for the $\mathrm{K}^{+}$removal from juices with pulp (e.g. the most popular in the USA orange juice). Currently there are no commercially available low $\mathrm{K}^{+}$fruit/vegetable juices for renal patients nor do patients have the ability to lower the $\mathrm{K}^{+}$in juices on an individual basis. A device is reported that individual patients can use to remove $\mathrm{K}^{+}$from juices with or without pulp using permeable t-sacs with Dowex Monosphere 99/320 Ca cation-exchange resin. The device significantly lowers the $\mathrm{K}^{+}$ content (by $\sim 80 \%$ of original), is simple to use, and will be of benefit to patients who are on $\mathrm{K}^{+}$restricted diets.
\end{abstract}

Keywords: Diet, Potassium, Chronic Kidney Disease, Juice

\section{Introduction}

There are currently estimated about 20 million patients with chronic kidney disease (CKD) in the USA and above 100 million worldwide [1, 2]. Patients with CKD stages 3-5 are hyperkalemic because of decreased/lost ability of their kidneys to excrete $\mathrm{K}^{+}$. Hyperkalemia that may cause heart attack plays an important role in patient morbidity/mortality. To prevent hyperkalemia in these patients, the $\mathrm{K}^{+}$intake is restricted by decreasing the consumption of high $\mathrm{K}^{+}$content fruits, vegetables, and juices [1-10].

Currently there are no commercially available low $\mathrm{K}^{+}$ fruit/vegetable juices for renal patients nor do patients have the ability to lower the $\mathrm{K}^{+}$in juices on an individual basis. There have been previous attempts to remove $\mathrm{K}^{+}$from juices and other beverages. The $\mathrm{Na}^{+}$-charged polystyrene sulfonate (Kayexalate) used orally while ingesting food to absorb dietary $\mathrm{K}^{+}$led to gastrointestinal (GI) side effects and release of $\mathrm{Na}^{+}$that could lead to excess $\mathrm{Na}^{+}$absorption [8-15]. The $\mathrm{Ca}^{2+}$-charged cation exchangers did not release $\mathrm{Na}^{+}$in the GI system but had significantly lower $\mathrm{K}^{+}$binding capacity [1516]. New $\mathrm{K}^{+}$binding compounds such as Veltassa (Patiromer) and ZS-9 will potentially replace Kayexalate [8]. ZS-9 is still not approved by the FDA. Veltassa is restricted to being used after six hours of having ingested any other oral drug. Both compounds require more studies of potential interference with other drugs. Therefore, lowering the $\mathrm{K}^{+}$ content of food before it is consumed may be a helpful 
approach to improve the variety of the diet of kidney patients. Towards this goal, large scale ion-exchange column chromatography can be used to remove $\mathrm{K}^{+}$from juices without pulp [15-21], however this approach has not been utilized to create commercial products.

Pulp containing orange and grapefruit juices are very popular in the US and other countries, and are recommended by dieticians as important components of a heart healthy diet. Given that there are no commercially available fruit juices with or without pulp that have a reduced $\mathrm{K}^{+}$content, and furthermore, patients do not have the ability to lower the $\mathrm{K}^{+}$ content of juices with or without pulp on an individual basis, the goal of this study was to develop a simple and safe single-use device for CKD and ESRD patients that removes $\mathrm{K}^{+}$from juices with and without pulp.

\section{Materials and Methods}

\subsection{Potassium Removal Device}

Dowex Monosphere 99/320 Ca cation-exchange resin beads were kindly provided by Donna DeFlavis (Dow Chemical) was used in the devices created to remove $\mathrm{K}^{+}$ from juices with pulp (orange and grapefruit). Juices without pulp were used in some experiments for comparison. The Dowex beads were weighed, placed in t-sac bags ( $\mathrm{T}$-Sac Hannover, Germany), then thermosealed using an Impulse Sealer (American International Electric) and equilibrated with water. The water was decanted and juice was added. The data were acquired with or without rotation. The container was rotated either manually or on a mechanical rotator for various times and rotation frequency (Fig. 1). The experiments were performed at room temperature or $4^{\circ} \mathrm{C}$.
A

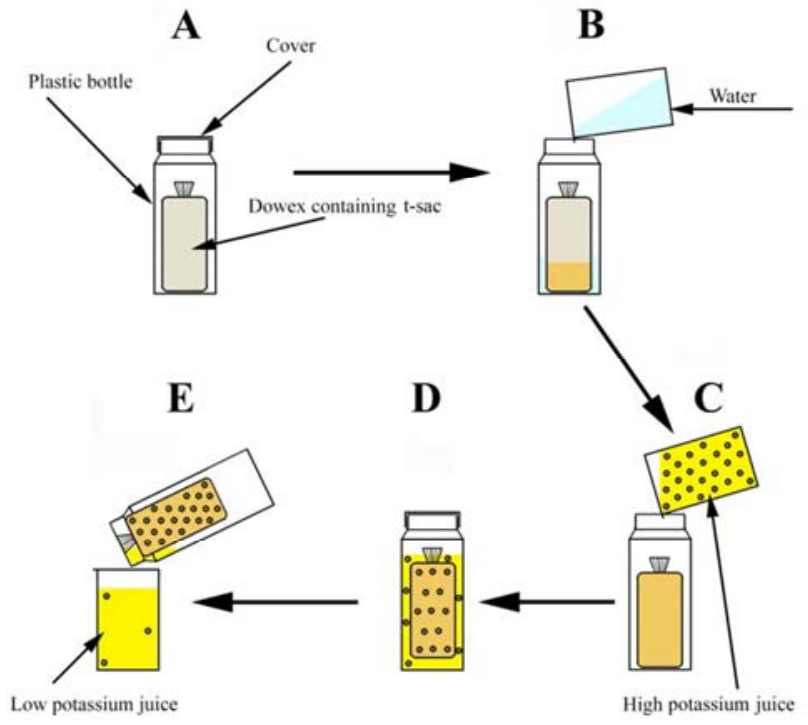

Figure 1. Schematic presentation of the $K^{+}$removal process from juices. A tsac with Dowex Monosphere 99/320 Ca cation-exchange resin (grey) was placed in a plastic container (A). The resin was equilibrated with water (B, brown). After water decantation, the juice was added to the container $(C)$, and the container was rotated manually or mechanically for $20 \mathrm{~min}(D)$. The low $K^{+}$juice was collected $(E)$.

\subsection{Juices}

We used pulp containing orange, grapefruit, grape juices and pulp free apple. Orange and grapefruit juices contained $48.6 \mathrm{mEq} / \mathrm{L}$ and $30 \mathrm{mEq} / \mathrm{L} \mathrm{K}^{+}$respectively. Apple and grape juices contained $24-30 \mathrm{mEq} / \mathrm{L}$ and $17-20 \mathrm{mEq} / \mathrm{L} \mathrm{K} \mathrm{K}^{+}$ respectively.

\section{3. $\mathrm{K}^{+}, \mathrm{Ca}^{2+}$, and $\mathrm{pH}$ Measurements}

The $\mathrm{K}^{+}$and $\mathrm{Ca}^{2+}$ concentrations of the juices were measured on a Cobas c 311/501 analyzer (Roche). This analyzer measures the $\mathrm{K}^{+}$concentration using a $\mathrm{K}^{+}$selective electrode and the Roche Calcium Gen. 2 reagent to measure the $\mathrm{Ca}^{2+}$ concentration photometrically [22]. The $\mathrm{pH}$ of the juices was measured using an Orion $4 \mathrm{pH}$ meter (Thermo Electron).

\subsection{Statistics}

All experiments were replicated at least 4 times. The data are reported as mean \pm standard error.

\section{Results}

\subsection{Effect of Incubation Time}

Figure 2 illustrates the $\mathrm{K}^{+}$removal from orange juice at a constant Dowex beads to juice ratio of 1:1 with and without mechanical rotation. The 1:1 Dowex beads to juice ratio was the maximum ratio that provided complete immersion of the $\mathrm{t}$-sac. Most of the $\mathrm{K}^{+}$was removed in the first $20 \mathrm{~min}$ both with and without rotation. There were no significant differences in the $\mathrm{K}^{+}$ removal rate between $1 \mathrm{~h}$ and 2-day incubation. Without rotation only $\sim 33 \%$ of the original $\mathrm{K}^{+}$was removed whereas with rotation, $\sim 90 \%$ of the original $\mathrm{K}^{+}$was removed.

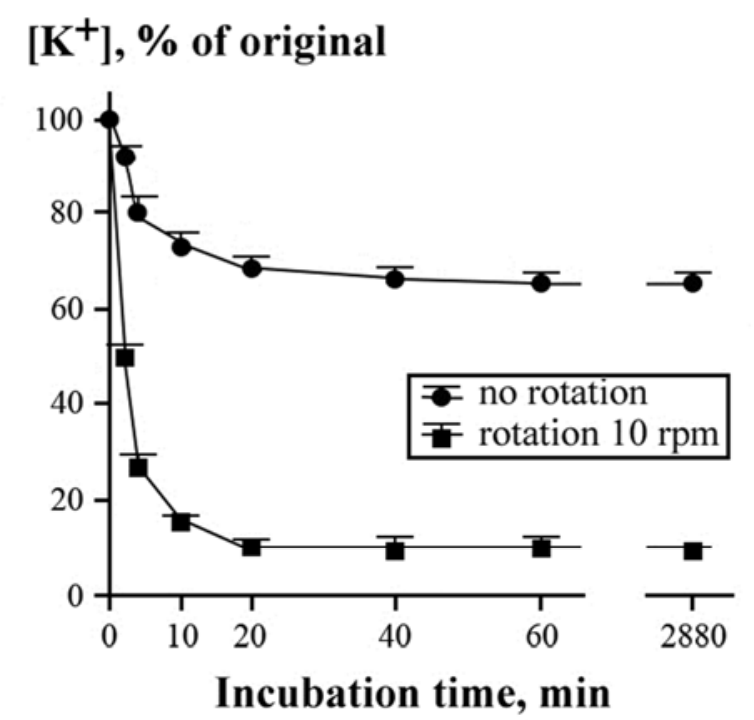

Figure 2. Effect of rotation on $K^{+}$removal from orange juice with medium pulp. A single $t$-sac with $120 \mathrm{~g}$ Dowex Monosphere 99/320 Ca cationexchange resin was incubated at room temperature in a plastic container with $120 \mathrm{~mL}$ orange juice without and with mechanical rotation of $10 \mathrm{rpm}$. The juice aliquots were collected at various times and used for $K^{+}$ measurements. 


\subsection{Effect of the Juice to Dowex Beads Ratio}

The effect of the Dowex beads to juice ratio on the rate of $\mathrm{K}^{+}$removal was further studied. Figure 3. illustrates the time dependence of $\mathrm{K}^{+}$removal from orange juice at $1: 1$ to $1: 5$ Dowex beads to juice ratios. At Dowex beads/orange juice ratios of $1: 1$ and $1: 2$, above $90 \%$ and $\sim 80 \%$ respectively of initial $\mathrm{K}^{+}$was removed in $20 \mathrm{~min}$. At a Dowex beads/orange juice ratio of $1: 5, \sim 65 \%$ of the initial $\mathrm{K}^{+}$was removed in 30 min that was not significantly changed by increasing the incubation time. Based on this data, in subsequent experiments a Dowex beads to juice ratio of 1:2 that removed $\sim 80 \%$ of the original $\mathrm{K}^{+}$level in 20 min was used.

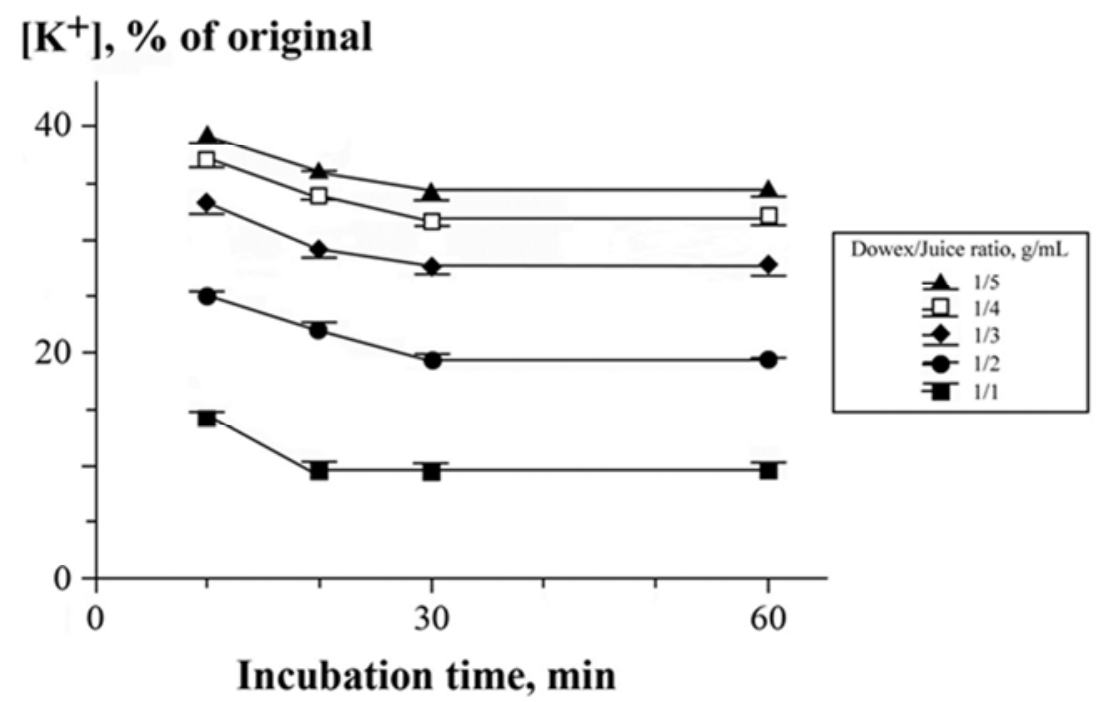

Figure 3. Effect of the Dowex beads to juice ratio on $K+$ removal from orange juice with medium pulp. A single $t$-sac with various amounts of Dowex beads was placed in a plastic container with $120 \mathrm{~mL}$ of a medium pulp orange juice. The container was rotated mechanically at 5 rpm at room temperature, and aliquots for $K+$ measurements were collected at various times.

\subsection{Effect of Rotation Rate}

Figure 4 shows that increase of the rotation rate from 0.2 to $10 \mathrm{rpm}$ elevates the $\mathrm{K}^{+}$removal rate from orange juice. At 20 min incubation, both 10 and $5 \mathrm{rpm}$ rotation rates provided $\sim 80 \%$ removal of the original $\mathrm{K}^{+}$level. Results obtained with mechanical and manual rotation did not demonstrate significant differences.

\section{$\left[\mathrm{K}^{+}\right]$, \% of original}

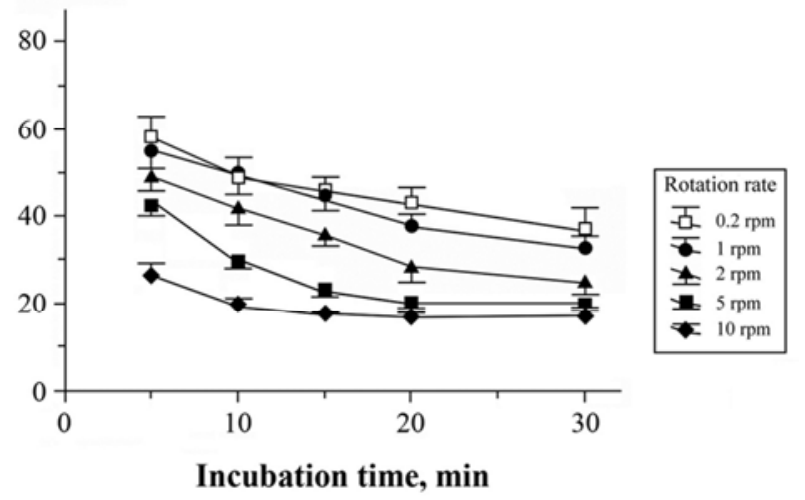

Figure 4. Effect of the rotation rate (manual rotation) on the $K^{+}$removal from orange juice with medium pulp after incubation with a single t-sac containing $120 \mathrm{~g}$ Dowex beads (beads to juice ratio 1:2) at room temperature. Aliquots were collected after 5-30 min incubation and used for $K^{+}$measurements.

\subsection{Effect of T-sac Surface Area}

Figure 5 illustrates the effect of sac surface at a constant
Dowex beads to juice ratio of $1: 4$ on the $\mathrm{K}^{+}$removal from orange juice. To increase the surface area using the same amount of Dowex beads, the number of $\mathrm{t}$-sacs using proportionally less Dowex beads per $\mathrm{t}$-sac was increased. Increasing the surface area $\sim 2.5$ fold ( $35 \mathrm{t}$-sacs) removed $\sim 77 \%$ of the original $\mathrm{K}^{+}$at a Dowex beads to juice ratio of $1: 4$ that was not significantly different from the $\mathrm{K}^{+}$removal efficiency obtained using a single t-sac with a Dowex beads to juice ratio of 1:2. This approach uses $\sim 50 \%$ less Dowex beads.

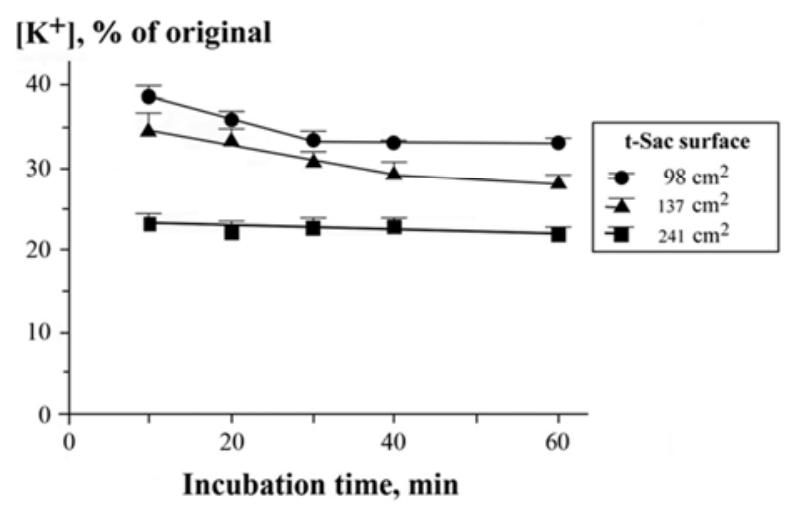

Figure 5. Effect of $t$-sac surface area on $\mathrm{K}^{+}$removal from orange juice with medium pulp at a constant Dowex beads to juice ratio of 1:4. Sixty $g$ of Dowex beads were used all experiments. Single $t$-sac $\left(98 \mathrm{~cm}^{2}\right.$ surface area), $6 \mathrm{t}$-sacs $\left(137 \mathrm{~cm}^{2}\right.$ surface area), and $35 \mathrm{t}$-sacs $\left(241 \mathrm{~cm}^{2}\right.$ surface area) were placed in a container with $240 \mathrm{~mL}$ medium pulp orange juice and incubated in a mechanical rotator at $10 \mathrm{rpm}$ at room temperature. Aliquots were collected after 10-60 min incubation and used for $\mathrm{K}^{+}$measurements. 


\subsection{Calcium Release, Potassium Removal and pH Changes in Juices with and Without Pulp}

$\mathrm{K}^{+}$was removed from juices in exchange for $\mathrm{Ca}^{2+}$. Figure 6A illustrates this process in orange and grapefruit juices. The device also efficiently removed $\mathrm{K}^{+}$from juices without pulp (apple and grape juices) in exchange for $\mathrm{Ca}^{2+}$ (Fig. 6B). The amount of released $\mathrm{Ca}^{2+}$ slightly exceeded the amount of removed $\mathrm{K}^{+}$suggesting that other cations were also removed from the juices in exchange for $\mathrm{Ca}^{2+}$.
Orange juice

$\left[\mathrm{K}^{+}\right]$or $\left[\mathrm{Ca}^{2+}\right], \mathrm{mEq} / \mathrm{L}$

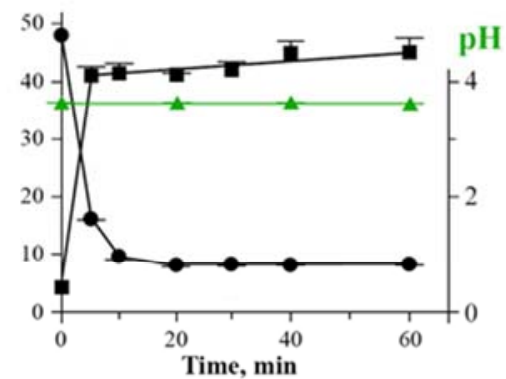

\section{A}

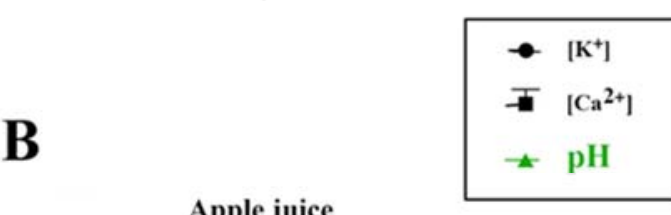

Apple juice

$\left[\mathrm{K}^{+}\right]$or $\left[\mathrm{Ca}^{2+}\right], \mathrm{mEq} / \mathrm{L}$

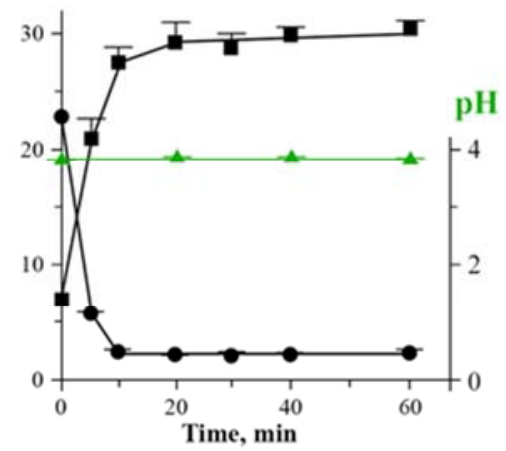

\section{Grapefruit juice}

$\left[\mathrm{K}^{+}\right]$or $\left[\mathrm{Ca}^{2+}\right], \mathrm{mEq} / \mathrm{L}$

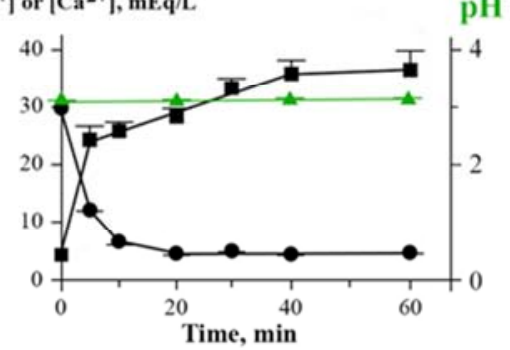

Grape juice

$\left[\mathrm{K}^{+}\right]$or $\left[\mathrm{Ca}^{2+}\right], \mathrm{mEq} / \mathrm{L}$

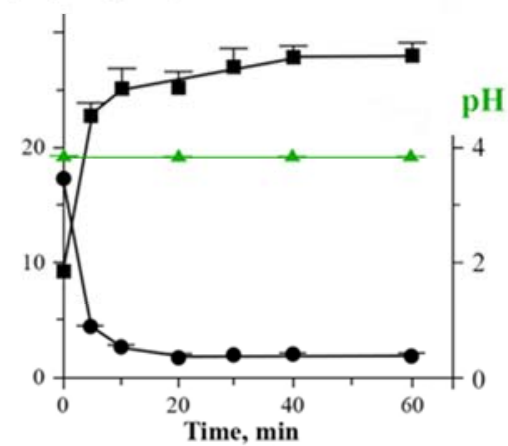

Figure 6. $\mathrm{Ca}^{2+}$ release, $\mathrm{K}^{+}$removal and $\mathrm{pH}$ changes in juices with pulp (A, orange and grapefruit juices) and without pulp (B, apple and grape juices). A single t-sac with $120 \mathrm{~g}$ Dowex beads was placed in a container with $240 \mathrm{~mL}$ of juice, and mechanically rotated at $10 \mathrm{rpm}$ at room temperature. Aliquots were collected after 5-60 min incubation and used for $\mathrm{K}^{+}, \mathrm{Ca}^{2+}$, and $\mathrm{pH}$ measurements.

No significant $\mathrm{pH}$ changes were detected in orange, grapefruit, apple and grape juices after $\sim 80 \%$ removal of the original $\mathrm{K}^{+}$content.

\section{Discussion}

We report here a new device to decrease the $\mathrm{K}^{+}$content of juices with and without pulp that can be widely used by CKD and ESRD patients The new device is simple, portable, and capable of removing $\mathrm{K}^{+}$from a single drink $(\sim 240 \mathrm{~mL})$ by an individual patient in $\sim 20 \mathrm{~min}$. The use of $\mathrm{t}$-sacs prevented admixture of the juice with the Dowex beads and possible ingestion of the Dowex beads [14, 16, 17]. The device achieves an $\sim 80 \%$ decrease in the original $\mathrm{K}^{+}$level in orange, grapefruit, apple and grape juices without a significant change of their $\mathrm{pH}$. Using Dowex Monosphere 99/320 Ca cation-exchange beads $\mathrm{Ca}^{2+}$ is exchanged for $\mathrm{K}^{+}$(rather than $\mathrm{H}^{+}$or $\mathrm{Na}^{+}$). This method can be potentially used for $\mathrm{K}^{+}$ removal from juices with pulp that were not tested in this study including carrot and tomato juices that contain respectively 17.7 and $14.3 \mathrm{mEq}$ per $240 \mathrm{~mL}$ equal to $23-34 \%$ and $18.5-27 \%$ of the daily allowed $\mathrm{K}^{+}$consumption in kidney patients. The device can also be potentially used for $\mathrm{K}^{+}$ removal from beverages such as infant formula $(10 \mathrm{mEq} / 240$ $\mathrm{mL}$ ) for pediatric renal patients.

It is difficult to estimate the total additional cost per juice given unknowns such as large scale production costs, potential future Medicare reimbursement, differences among cost structures and reimbursement schemes in various countries etc. It is believed that despite the added cost per juice, our devices could potentially find wide spread use globally given the prevalence and incidence of CKD and 
ESRD in countries such as USA, Japan, Taiwan, China, Brazil and Germany representing more than $50 \%$ of world kidney patients $[1,2]$. Importantly, decreasing some of the dietary restrictions of CKD and ESRD by offering them the ability to ingest a variety of juices has the added advantage of potentially improving their quality of life [23]. Furthermore, the current practice of restricting dietary $\mathrm{K}^{+}$in beverages can deprive dialysis patients of heart healthy juices [7]. In addition, if the juice intake of CKD and ESRD patients was less restricted, the quality of their diet with regards to vitamin, fiber, microelement intake would also potentially improve.

\section{Conclusions}

A novel method that individual users can use to significantly lower the $\mathrm{K}^{+}$content ( $20 \%$ of original) of their juices without changes of $\mathrm{pH}$ is reported. The widespread availability of "low K" juices for CKD and ESRD patients worldwide can potentially offer these patients a nutritionally improved and less restricted diet without the associated risk of their developing hyperkalemia.

\section{Acknowledgements}

The authors thank Donna DeFlavis (Dow Chemical) and Dow Chemical company for providing Dowex Monosphere 99/320 Ca cation-exchange resin. I. Kurtz is supported in part by funds from the NIH (R01-DK077162), the Allan Smidt Charitable Fund, the Factor Family Foundation Chair in Nephrology, and the Arvey Foundation. Ira Kurtz and Alexander Pushkin are inventors on the US Provisional Patent Application 62/296,328 titled "Devices and Methods for Decreasing Potassium Content in a Beverage".

\section{References}

[1] ESRD Patients in 2012. A Global Perspective. (2013). http://www.visionfmc.com/files/pdf_2/ESRD_Patients_2012.pdf.

[2] World Kidney Day: Chronic Kidney Disease. (2015). http://www.worldkidneyday.org/faqs/chronic-kidney-disease/. Access: 06/06/2016.

[3] Couser, W. G.; Remuzzi, G.; Mendis, S. and Tonelli, M. (2011). The contribution of chronic kidney disease to the global burden of major noncommunicable diseases. Kidney Int., 80, 1258-1270.

[4] Gekle, M. I. (2016). Kidney and aging - A narrative review. Exp. Gerontol., 2016 Mar 24. pii: S0531-5565(16)30081-X. doi: 10.1016/j.exger.2016.03.013. [Epub ahead of print].

[5] Jha, V.; Garcia-Garcia, G.; Iseki, K.; Li, Z.; Naicker, S.; Plattner, B.; Saran, R.; Wang, A. Y-M. and Yang, C. W. (2013). Chronic kidney disease: global dimension and perspectives. Lancet, 382, 260-272.

[6] Levey, A. S.; Atkins, R.; Coresh, J.; Cohen, E. P.; Collins, A. J.; Eckardt, K. U.; Nahas, M. E.; Jaber, B. L.; Jadoul, M.;
Levin, A.; Powe, N. R.; Rossert, J.; Wheeler, D. C.; Lameire, N. and Eknoyan, G. (2007). Chronic kidney disease as a global public health problem: approaches and initiatives - a position statement from Kidney Disease Improving Global Outcomes. Kidney Int. , 72, 247-259.

[7] Kalantar-Zadeh, K.; Tortorici, A. R.; Chen, J. L.; Kamgar, M.; Lau, W. L.; Moradi, H.; Rhee, C. M.; Streja, E. and Kovesdy, C. P. (2015). Dietary restrictions in dialysis patients: is there anything left to eat? Semin. Dial., 28, 159-168.

[8] Stern, R. H.; Grieff, M. and Bernstein, P. L. (2016). Treatment of hyperkalemia: something old, something new. Kidney Int., $89,546-554$.

[9] Hagan, A. E.; Farrington, C. A.; Wall, G. C. and Belz, M. M. (2016). Sodium polystyrene sulfonate for the treatment of acute hyperkalemia: a retrospective study. Clin. Nephrol., 85, $38-43$.

[10] Harel, Z.; Harel, S.; Shah, P. S.; Wald, R.; Perl, J. and Bell, C. M. (2013). Gastrointestinal adverse events with sodium polystyrene sulfonate (Kayexalate) use: a systematic review. Am. J. Med., 126, 264. e9-264. e24.

[11] Lillimoe, K. D.; Romolo, J. L.; Hamilton, S. R.; Pennington, L. R.; Burdick, J. F. and Williams, G. M. (1987). Intestinal necrosis due to sodium polystyrene (Kayexalate) in sorbitol enemas: clinical and experimental support for the hypothesis. Surgery, 101, 267-272.

[12] Ohlsson, A. and Hosking, M. (1987). Complications following oral administration of exchange resins in extremely low-birthweight infants. Eur. J. Pediatr., 146, 571-574.

[13] Sherman, S.; Friedman, A. P.; Berdon, W. E. and Haller, J. O. (1981). Kayexalate. A new cause of neonatal bowel opacification. Pediatr. Radiol., 138, 63-64.

[14] Chaaban, A.; Abouchacra, S.; Gebran, N.; Abayechi, F.; Hussain, Q.; Al Nuaimi, N. and Hassan, M. E. (2013). Potassium binders in hemodialysis patients: a friend or foe? Ren. Fail., 35, 185-188.

[15] Bunchman, T. E.; Wood, E. G.; Schenck, M. H.; Weaver, K. A.; Klein, B. L. and Lynch, R. E. (1991). Pretreatment of formula with sodium polystyrene sulfonate to reduce dietary potassium intake. Pediatr. Nephrol., 5, 29-32.

[16] Levy, N.; Boxer, J. and Carter, A. (1973). Citrus juice treated with exchange resins. N. Engl. J. Med., 289, 753-754.

[17] Cacioppo, P. L. and Hollander, L. (1972). Orange juice treated with exchange resin. N. Engl. J. Med., 287, 361.

[18] Rivard, A. L.; Raup, S. M. and Beilman, G. J. (2004). Sodium polystyrene sulfonate used to reduce the potassium content of a high-protein enteral formula: a quantitative analysis. JPEN J. Parenter. Enteral. Nutr., 28, 76-78.

[19] Schröder, C. H.; van den Berg, A. M. J.; Willems, J. L. and Monnens, L. A. H. (1993). Reduction of potassium in drinks by pre-treatment with calcium polystyrene sulphonate. Eur. J. Pediatr., 152, 263-264.

[20] Thompson, K.; Flynn, J.; Okamura, D. and Zhou, L. (2013). Pretreatment of formula or expressed breast milk with sodium polystyrene sulfonate (Kayexalate $(\circledR)$ ) as a treatment for hyperkalemia in infants with acute or chronic renal insufficiency. J. Ren. Nutr., 23, 333-339. 
[21] Van Kamp, G. J.; Bakker, W. and Rosier, J. G. M. C. (1975). Removal of potassium from fruit juices by ion exchange. $\mathrm{Br}$. Med. J., 1, 512-513.

[22] Bourguignon, C.; Dupuy, A. M.; Coste; T., Michel, F. and Cristol, J. P. (2014). Evaluation of NM-BAPTA method for plasma total calcium measurement on Cobas $8000 \AA$. Clin. Biochem., 47, 636-639.
[23] Tsai, Y. C.; Hung, C. C.; Hwang, S. J.; Wang, S. L.; Hsiao, S. M.; Lin, M. Y.; Kung, L. F.; Hsiao, P. N. and Chen, H. C. (2010). Quality of life predicts risks of end-stage renal disease and mortality in patients with chronic kidney disease. Nephrol. Dial. Transplant., 25, 1621-1626. 